\title{
Research Status of Innovative Industrial Clusters in China Based on Bibliometric Analysis
}

\author{
Pan Zhang \\ School of Economics \& Commerce, Guangdong University of Technology, Guangzhou, China
}

\begin{abstract}
The development of innovative industrial clusters is an important way to promote the development of innovative enterprises in China. At the same time, it also has definite practical significance to encourage regional innovation. This paper uses the CNKI database as the research platform, and selects the literature in the field of innovative industrial clusters from 2002 to March 1, 2021 as the research object, using bibliometrics method and CiteSpace software tools to analyze the number of publications, cooperative institutions, research hotspots, and trends. Perform visual analysis and systematically comb the progress status of innovative industrial clusters and predict future research trends in China. The research results show that the research on the basic theories of innovation industry clusters is not solid enough in China, and the cooperation between scientific research institutions needs to be strengthened; in addition, in this paper, the research process is divided into the embryonic exploration period and the development period for analysis, and then found it Related research hotspots mainly focus on innovative industrial clusters and industrial cluster theory, innovative industrial cluster development areas, innovative enterprises and government policies.
\end{abstract}

\section{Introduction}

In recent years, the overall capacity of scientific and technological innovation has been constantly improved in China. From the basic innovation to the rise of the development of innovative industries, speeding up the development of innovative industrial clusters has become a key force in the development of innovative enterprises in China. In April 2020, the Torch Center of the Ministry of Science and Technology, based on the pilot and cultivation of existing innovative industrial clusters, and in accordance with the "Opinions on Further Promoting the High-quality Development of Industrial Clusters", proposed to give full play to the industrial agglomeration role of the National High-tech Zone and speed up Build innovative industrial clusters to promote regional collaborative innovation and the development of hightech industries. Judging from the existing research results, innovative industrial clusters evolved from industrial clusters and innovation clusters, and can be regarded as modern industrial clusters after transformation and upgrading. The concept of industrial clusters was first proposed by Michael. It refers to companies, suppliers, financial institutions, manufacturers and other related institutions that have a competitive and cooperative relationship in a specific area, are geographically concentrated, and has interactions ${ }^{1}$. The innovation cluster is composed of enterprises, research institutions, universities and related intermediary service organizations, in the form of strategic alliances and cooperation, so as to form a technology-economic network characterized by agglomeration economy and a large number of knowledge spillovers ${ }^{2}$. Based on the existing literature, an innovative industrial cluster refers to the gathering of enterprises, $R \& D$, and service institutions associated with the industrial chain in a specific area, in the form of division of labor and collaborative innovation, and then forming a crossindustry and cross-regional drive Role and international competitiveness of the industrial organization ${ }^{3}$.

At the existing theoretical level, most scholars at home and abroad have conducted research based on the concept, characteristics, interaction mechanism and performance evaluation system of innovative industrial clusters, so as to study the development path and mode of promoting innovative industrial clusters. For example, Lynn et $\mathrm{al}^{4}$ believe that innovative industrial clusters are an advanced stage of industrial cluster development based on the internal relationships of industrial clusters. Compared with the traditional industrial clusters period, they pay greater attention to the innovative connection between the internal entities of the cluster. Based on the recognized concept of industrial clusters, Wang Jici ${ }^{5}$ proposed the importance of upgrading from basic industrial clusters to innovative industrial clusters from multiple perspectives such as globalization, industrial organization, and technological innovation, and mentioned in the article the development and innovation. Industrial clusters have a key role in my country's modern industrialization path, and on this basis. Relevant policy recommendations have also been proposed. 
At present, research on innovative industrial clusters is still at the basic stage in China, and the corresponding theoretical research is relatively one-sided, lacking a quantitative perspective of systematic analysis and framework research. Therefore, in order to systematically understand the development trend of innovative industrial cluster research in China, this paper will use the bibliometric analysis of the innovative industrial cluster field, combined with qualitative research, to find out the current research hotspots and its changing trends in this field, and further promote China's research and practice of innovative industrial clusters.

\section{Research methods and data sources}

Bibliometrics is a quantitative analysis method for studying the external characteristics of documents. It forms and developed on the basis of mathematical and statistical methods. ${ }^{6}$ Bibliometric research is mainly to derive the required target literature data through the literature database, and then perform keyword co-words and cluster analysis on it, but the conclusions obtained by such research are easily affected by some subjective factors, which will lead to deviations in the conclusions ${ }^{7}$. CiteSpace software was designed by Professor Chen Chaomei from Drexel University in the United States on the basis of the Java language ${ }^{8}$. It is a visual analysis tool employed to discuss development trends and significant changes in established research fields ${ }^{9}$. With continuous enhancement of CiteSpace algorithms and functions, it has been widely implemented in computer science, information science and medicine. There are more and more researches in the field of the combination of bibliometrics and CiteSpace, especially in some domestic and foreign review articles, the use of bibliometrics has played a good quantitative analysis effect on it $^{10}$, but in innovation Topic research on type industrial clusters is relatively scarce.

This paper adopts the bibliometric method and CiteSpace software to visually analyze the literature in the sample from the perspective of the knowledge map, analyze the development status and structural relationship of scientific knowledge in the field of innovative industrial clusters, and explore future research hotspots and trends in this field. Using CNKI document database as the original data source, and use the advanced search box of Hownet to enter the subject of "innovative industrial clusters". The time span is taken from 2002 to March 1, 2021. A total of 699 data were retrieved, of which the earliest of the related literature was made available in 2002. The documents retrieved from the database were screened one by one, and some literature data such as articles, newspapers and short reviews that were not closely related to the main body of the innovative industrial cluster were deleted, and finally 436 effective research documents in the field of innovative industrial clusters were obtained.

\section{Hot spots and development trends of sample literature research}

\subsection{Keyword frequency analysis}

This part import retrieved data into the CiteSpace software, selects the node type as "keyword", uses the algorithm to facilitate the network, and draws the corresponding keyword knowledge graph as Figure 1. A total of 116 keyword nodes and 148 connections are made. Each circular node in the figure is a keyword. The more occurrences, the larger the circle, indicating that it is a research hotspot in this field; the lower the occurrence, the smaller the circle. Depending on the information presented in the figure, the lines in the figure are more connected, indicating that there is a close connection between each keyword. In addition to the keyword connection and node size, the keyword centrality can also reflect the research hotspot in this field to a certain extent, that is, the keyword centrality is greater than 0.1 , indicating that it is a research hotspot ${ }^{11}$. In CiteSpace, can relate to the frequency and centrality of each keyword. Table 1 show in the top 20 hot keywords and the corresponding centrality in the research field of innovative industrial clusters in China. 8 keywords are under a centrality greater than 0.1 . Key words such as groundbreaking industrial clusters, industrial clusters, innovative cities, high-tech zones, innovative science and technology parks, and innovative enterprises are more prominent, taking into consideration the research hotspots in the field of innovative industrial clusters.

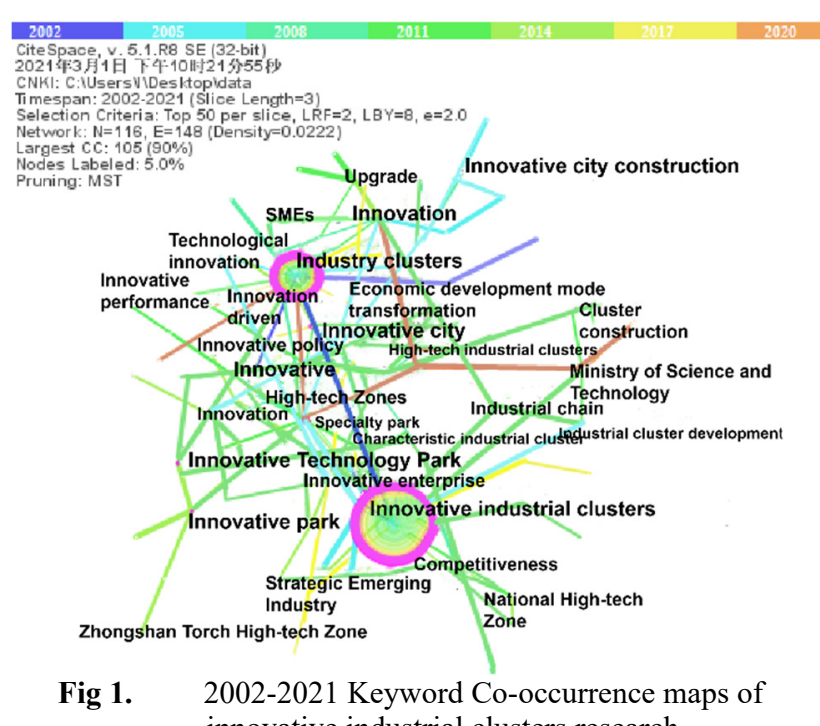
innovative industrial clusters research. 
Table1. 2002-2021 The main high-frequency keywords in the research of innovative industrial clusters.

\begin{tabular}{|c|c|c|c|}
\hline $\begin{array}{l}\text { Serial } \\
\text { number }\end{array}$ & Keywords & $\begin{array}{l}\text { frequenc } \\
y\end{array}$ & $\begin{array}{l}\text { Centrali } \\
\text { ty }\end{array}$ \\
\hline 1 & $\begin{array}{l}\text { Innovative industrial } \\
\text { clusters }\end{array}$ & 203 & 0.82 \\
\hline 2 & Industrial clusters & 141 & 0.71 \\
\hline 3 & Innovative & 27 & 0.08 \\
\hline 4 & Innovative city & 26 & 0.25 \\
\hline 5 & High-tech Zones & 25 & 0.2 \\
\hline 6 & Innovation & 20 & 0.16 \\
\hline 7 & Innovative enterprise & 17 & 0.17 \\
\hline 8 & $\begin{array}{l}\text { Ministry of Science } \\
\text { and Technology }\end{array}$ & 15 & 0.13 \\
\hline 9 & $\begin{array}{l}\text { Strategic } \text { Emerging } \\
\text { Industry }\end{array}$ & 12 & 0.09 \\
\hline 10 & $\begin{array}{l}\text { National High-tech } \\
\text { Zone }\end{array}$ & 12 & 0.04 \\
\hline 11 & $\begin{array}{l}\text { High-tech industrial } \\
\text { clusters }\end{array}$ & 10 & 0.04 \\
\hline 12 & $\begin{array}{ll}\begin{array}{l}\text { Industrial } \\
\text { development }\end{array} & \text { cluster } \\
\end{array}$ & 10 & 0.01 \\
\hline 13 & Competitiveness & 8 & 0.08 \\
\hline 14 & $\begin{array}{l}\text { Innovative } \\
\text { Technology Park }\end{array}$ & 8 & 0.18 \\
\hline 15 & $\begin{array}{ll}\begin{array}{l}\text { Innovative } \\
\text { construction }\end{array} & \text { city } \\
\end{array}$ & 6 & 0.04 \\
\hline 16 & Cluster construction & 5 & 0.01 \\
\hline 17 & $\begin{array}{l}\text { Economic } \\
\text { development mode } \\
\text { transformation }\end{array}$ & 5 & 0.08 \\
\hline 18 & SMEs & 5 & 0.01 \\
\hline 19 & Innovation driven & 5 & 0.03 \\
\hline 20 & Innovative park & 4 & 0.03 \\
\hline
\end{tabular}

\subsection{Cluster analyses of research hotspots}

In order to further cluster analysis of hot keywords, this part will use CiteSpace software and select LSI algorithm for clustering to obtain a keyword clustering map for the research of innovative industrial clusters in my country. According to Figure 2, the clustering module value $Q$ is $0.634(\mathrm{Q}>0.3)$, and the cluster average contour value $\mathrm{S}$ is 0.7033 (greater than 0.5). Therefore, this indicates that the clustering structure is significant and the clustering is reasonable, but some of the clusters are There are intersections and overlaps between the areas, indicating that there is a certain integration and diversion between the research in the field of innovative industrial clusters and other clusters. It can be seen from the document cocitation network that there are 9 clusters of keywords related to the field of innovative industrial clusters, namely \#0 innovative industrial clusters, \#1 high-tech zones, \#2 industry clusters, and \#3 innovative city, \#4 economic development mode transformation, \#5 innovative park, \#6 government public policy, \#7 innovative city construction and $\# 8$ technological innovation diffusion.

Compared with the development of some foreign innovative industrial clusters, China's innovative industrial clusters have developed slowly, especially in terms of development models and mechanisms. Although the term "innovative industrial clusters" appeared earlier in China, there are few related theoretical research documents. Scholars have not done yet in-depth research on this and have not formed a systematic theoretical relationship system. Therefore, it is clear that innovative industrial clusters and the connection relationship between industrial clusters and innovative city construction are an important issue that needs to be resolved in the research and practice of innovative industrial clusters.

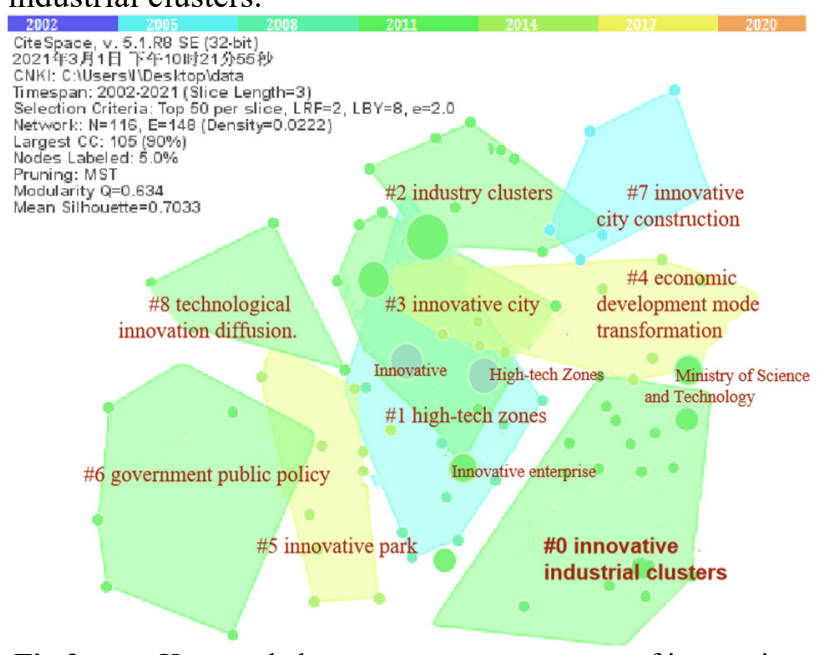

Fig 2. Keyword cluster co-occurrence maps of innovative industrial clusters from 2002 to 2021

\subsection{Research trends analyses}

The time zone map mainly represents the knowledge evolution map from the time dimension, and can clearly show the update hotspots of the literature and the interaction between the related literature ${ }^{12}$.Figure 3 is a period zone view of the hot research on innovative industrial clusters from 2002 to 2021. From the figure, it can be found that the evolution of groundbreaking industrial clusters research can be roughly divided into three stages: The first stage (2002-2005) is the embryonic and exploratory period of the research on innovative industrial clusters in China. This stage mainly be focused on the research on the connotation, innovative methods and development paths of innovative industrial clusters, involving industrial clusters, innovative enterprises and core competitiveness. The development paths are mostly focussed on the industry. Upgrade, technology and cultural innovation. The second stage (2006-2014) is the period of rapid development of research on innovative industrial clusters in China. During this stage, there are more literature studies on cluster construction and development regions. Innovative industrial clusters have gradually shown diversified models, and they have gradually become innovative. The proliferation of research on urban construction, strategic emerging industries and government policies. The third stage is taken from 2015 to the present. Due to the in-depth theoretical discussion of innovative industrial clusters and the peripheral radiation effects of related pilot enterprises, the emergent words are slightly reduced, and the number of documents with "innovative industrial clusters" as the key word is also available. And the recent emergence of keywords such as "technological business incubator", 
"high-quality development" and "Biomedicine" has become the research frontiers in this field.

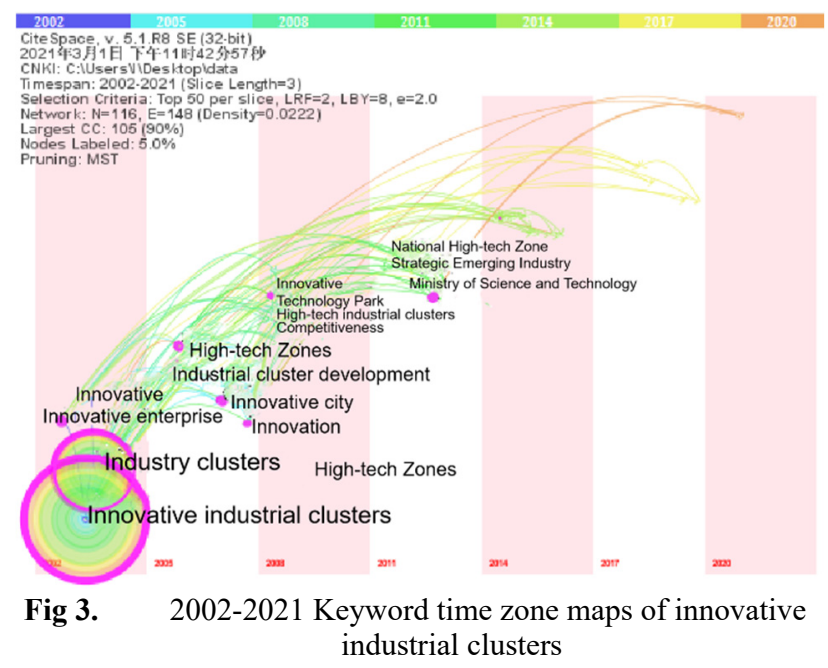

\section{Research conclusions}

Based on the CiteSpace visualization analysis software, this paper conducted a quantification analysis for the research literature in innovative industrial clusters field in 2002 to 2021, combing research hotspots and topics distributions in the field of innovative industrial clusters in China, and from the angle of evolution path Departure, analyze the emerging trend and focus of future research in China's innovative industrial clusters. The main conclusions are as following:

From the keywords, the centrality and frequency of the keyword, the research hotspot innovative industrial clusters in China mainly involve the research, innovative industrial clusters development regional research and innovative industrial clusters development model and mechanism research three main aspects. Although there are relatively few research hotspots in these three areas at present, in the future progress, due to the advancement of national policies, it is believed that these research hotspots will continue to deepen is enhanced, and get more attention from scholars.

From the perspective of the keyword time zone map, this article divides the evolutionary context of China's innovative industrial cluster research from 2002 to 2021 roughly into three stages, namely, the budding exploration stage from 2002 to 2005 , and the rapid development from 2006 to 2014. Stage, the sustainable development stage from 2015 to present. In the follow-up progress, it can be clearly seen that the research focus in the field of innovative industrial clusters have obvious policy inclination, and the emergence of some hot words is also closely following the promotion and implementation of policies. On the whole, the development of innovative industrial clusters in China is still in the deepening construction stage, and the regional development situation is still unstable. It is far from enough to rely on policy guidance. It also requires robust theories as a supporting point for continuous in-depth exploration.

\section{References}

1. Michael E P. The Competitive Advantage of Nations[M]. New York:Business \& Economics, 1990:120-130.

2. Zhong Shuhua. Innovation clusters: concept, characteristics and theoretical significance[J]. Science Research, 2008(01):178-184.

3. Torch High-Tech Industry Development Center, Ministry of Science and Technology. 2017 China Torch Statistical Yearbook [M]. Beijing: China Statistics Press, 2017:3-45.

4. Lynn M, Fulvia F. Local clusters, innovation systems and sus-tained compositeness[R]. The United Nations: The United Nations University, 1998.

5. Wang Jici. Policy Suggestions on the Development of Innovative Industrial Clusters[J]. Economic Geography, 2004(04):433-436.

6. Chen Weijun. Comparative Research on Bibliometric Method and Content Analysis Method[J]. Information Science, 2001(08):884-886.

7. Ke Lina, Yin Shusheng, Liu Wanbo. Bibliometric analysis of Chinese marine ecological economy based on CiteSpace[J]. Acta Ecologica Sinica, 2018,38(15):5602-5610.

8. Li Jie, Chen Chaomei. CiteSpace: Science and Technology Text Mining and Visualization [M]. Beijing: Capital University of Economics and Business Press, 2016.

9. Zhang Lu, Zhang Junbiao, Tong Qingmeng, Guo Qing. Agricultural Carbon Emission Research Progress: Bibliometric Analysis Based on CiteSpace[J]. Science and Technology Management Research, 2015,35(21):219-223.

10. Hu Dongbin, Yang Zhihui, Chen Xiaohong. A Bibliometric Analysis of the "Blockchain+" Business Model[J]. System Engineering Theory and Practice, 2021,41(01):247-264.

11. Wang Juan, Chen Xiang.The Digital Economic Research Status Based on Documentary Measurement [J]. Technology Economy, 2020,39 (01): 19-24.

12. Chen Yue, Chen Chaomei, Liu Zeyuan, Hu Zhigang, Wang Xianwen. Methodological function of CiteSpace knowledge graph[J]. Science Research, 2015,33(02):242-253. 